\title{
Study of pregnancy outcome in women with cardiac disease: a retrospective analysis
}

\author{
Kiran Pandey, Kavita Verma*, Shruti Gupta, Uruj Jahan, Neha Kirti, Pundrik Gupta
}

Department of Obstetrics and Gynaecology, GSVM Medical College, Kanpur, Uttar Pradesh, India

Received: 11 August 2016

Accepted: 06 September 2016

\section{*Correspondence:}

Dr. Kavita Verma,

E-mail: soni.kavita@yahoo.com

Copyright: $\odot$ the author(s), publisher and licensee Medip Academy. This is an open-access article distributed under the terms of the Creative Commons Attribution Non-Commercial License, which permits unrestricted non-commercial use, distribution, and reproduction in any medium, provided the original work is properly cited.

\section{ABSTRACT}

Background: Cardiac disease complicates 1\% of all pregnancies. It is one of the 3 major indirect causes of maternal mortality in India. Objective of the study is to evaluate the maternal and fetal outcome in patients with cardiac disease in pregnancy.

Methods: A retrospective analysis was carried out in 117 pregnant women with known or newly diagnosed heart disease from January 2013 to December 2015 at a tertiary care hospital.

Results: In the present study, the incidence of cardiac disease was $0.8 \%$. Majority $66(56.4 \%)$ were of $23-27$ years of age, $72(61.5 \%)$ were primigravida. Mostly $84(71.8 \%)$ belonging to New York Heart Association (NYHA) Class I and II. Rheumatic heart disease seen in $96(82.1 \%)$ and congenital heart disease in $17.9 \%$ subjects. Among RHD Mitral stenosis was the most common, seen in $51(53.1 \%)$ cases. Majority $78(66.6 \%)$ had vaginal delivery and caesarean section in $28(23.9 \%)$ cases. Most common maternal complication was anaemia seen in $54(46.2 \%)$ cases, congestive cardiac failure complicated $23(19.6 \%)$ cases. 18 patients required ICU care and maternal mortality in 6 cases $(5.12 \%)$. The live births in $(94.8 \%)$ cases, $33(28.2 \%)$ babies required NICU admission and perinatal mortality was $7.7 \%$.

Conclusions: Heart disease in pregnancy is a high risk condition and has a major impact on pregnancy outcome. Rheumatic heart disease being the prominent cardiac lesion. Fetomaternal mortality and morbidity can be reduced with proper antenatal, intrapartum and postnatal care in conjunction with cardiologist and neonatologist.

Keywords: Cardiac disease, RHD, Outcome, Pregnancy, Retrospective, NYHA class

\section{INTRODUCTION}

Cardiac disease during pregnancy is a challenge to obstetrician as common clinical features of cardiac lesions like breathlessness, pedal edema and murmur mimic normal pregnancy posing a diagnostic difficulty. ${ }^{1-4}$ Prevalence of heart disease in pregnancy vary from 0.3 $3.5 \%{ }^{6}$ Cardiac output increases by $30-50 \%$ during pregnancy and a further increase during labour and delivery imposes a burden on diseased heart leading to complications and death. Cardiac disorders contribute to approximately $20.5 \%$ of maternal deaths. ${ }^{1-5}$ The ratio of RHD:CHD is decreasing due to improved paediatric care and improved surgical interventions early in childhood. Increasing number of women with cardiac disease is reaching the reproductive age due to modern therapeutic options and moreover these patients are now attempting pregnancy multiple times due to improved availability of life saving modern therapy. ${ }^{7}$

Development of obstetric complications like anaemia, preeclampsia, preterm labour and fetal growth restriction are commonly seen in patients with heart disease, that further worsens the outcome and complicate the management. It is essential to thoroughly evaluate patients for underlying cardiovascular disease in order to 
promote optimal care during pregnancy that plays a major role in the outcome. ${ }^{8}$ Objective of the study was to evaluate the maternal and fetal outcome in patients with cardiac disease in pregnancy.

\section{METHODS}

The retrospective study was conducted in the department of obstetrics and gynaecology of GSVM medical college Kanpur, Uttar Pradesh, India. Total 117 pregnant women with history of cardiac disease or newly diagnosed for the first time in pregnancy admitted to obstetrics ward from January 2013 to December 2015 were included in the study. The data were obtained from review of medical records. Baseline data recorded including age, parity, gestational age, type of lesion, duration of disease, time of diagnosis, treatment history, New York heart association (NYHA) functional class, maternal complications, mode of delivery and indication of caesarean section, neonatal outcome and admission to NICU were noted. In case of maternal mortality the cause of death was noted. Patients were discharged after 10 days with proper postnatal advice.

\section{RESULTS}

A total of 117 pregnant women with cardiac disease were included in the study. Total no. of patients admitted for delivery during the study period were 14967, including 117 patients with cardiac disease.

Table 1: Demographic characteristics $(n=117)$.

\begin{tabular}{|ll|}
\hline Characteristics & No $(\%)$ \\
\hline Age (years) & No $(\%)$ \\
\hline $18-22$ & $15(12.8 \%)$ \\
$23-27$ & $66(56.4 \%)$ \\
$28-32$ & $27(23.1 \%)$ \\
$>32$ & $09(7.69 \%)$ \\
\hline Gravida & No $(\%)$ \\
\hline Primigravida & $72(61.5 \%)$ \\
Gravida 2 & $30(25.6 \%)$ \\
Gravida 3 0r more & $15(12.8 \%)$ \\
\hline Booking status & No $(\%)$ \\
\hline Booked & $78(66.6 \%)$ \\
Unbooked & $39(33.3 \%)$ \\
\hline Time of diagnosis & No $(\%)$ \\
\hline Before pregnancy & $74(63.2 \%)$ \\
After pregnancy & $43(36.7 \%)$ \\
\hline Gestational age at delivery & No $(\%)$ \\
\hline Term & $102(87.2 \%)$ \\
Preterm & $15(12.8 \%)$ \\
\hline NYHA class & No $(\%)$ \\
\hline I and II & $84(71.8 \%)$ \\
III & $21(17.9 \%)$ \\
IV & $12(10.3 \%)$ \\
\hline Habitat & No $(\%)$ \\
\hline Urban & $48(41.02 \%)$ \\
Rural & $69(58.9 \%)$ \\
\hline
\end{tabular}

Thus incidence of cardiac disease at our centre was $0.8 \%$. Out of 117 patients, majority $66(56.4 \%)$ were in the age group of 23-27 years. Among the 117 pregnant women $72(61.5 \%)$ were primigravida, $25.6 \%$ were second gravida and $12.8 \%$ were gravida 3 or more.

Most of the patients $84(71.8 \%)$ presented in NYHA Class I and II. In the study population, it was seen that the outcome worsened as the class of the disease increased, complications being more in NYHA class III and IV. Majority $102(87.2 \%)$ had term delivery and 15 (12.8\%) had preterm delivery. Out of 117 patients, $78(66.6 \%)$ were booked and $39(33.3 \%)$ were unbooked, 48 $(41.02 \%)$ from urban and $69(58.9 \%)$ from rural area. Most of the patients $74(63.2 \%)$ were diagnosed before pregnancy, 11(9.40\%) were diagnosed during labour (Table 1). Majority of the patients $96(82.1 \%)$ in the study had Rheumatic heart disease and rest had congenital heart disease $(17.9 \%)$ (Figure 1$)$. Most of the patients had single lesion $75(64.1 \%)$ and $42(35.9 \%)$ patients had more than one lesion.

Table 2: Distribution of cardiac lesions.

\begin{tabular}{|ll|}
\hline Cardiac lesion & No $(\%)$ \\
\hline Rheumatic heart disease & $96(82.1 \%)$ \\
\hline MS & $51(53.1 \%)$ \\
MR & $12(12.5 \%)$ \\
MS+MR & $30(31.3 \%)$ \\
AS & $09(9.4 \%)$ \\
MS+MR+PAH & $36(37.5 \%)$ \\
MR+TR & $24(25 \%)$ \\
\hline Congenital heart disease & $21(17.9 \%)$ \\
\hline ASD & $09(42.9 \%)$ \\
VSD & $06(28.6 \%)$ \\
MVP & $06(28.6 \%)$ \\
\hline
\end{tabular}

Table 3: Indications of caesarean section $(n=28)$.

\begin{tabular}{|ll|l|}
\hline Indications & Elective (21) & Emergency (07) \\
\hline Previous LSCS & $10(35.7 \%)$ & - \\
\hline $\begin{array}{l}\text { Cephalopelvic } \\
\text { disproportion }\end{array}$ & 01 & 01 \\
\hline $\begin{array}{l}\text { Non-progress of } \\
\text { labour }\end{array}$ & - & 02 \\
\hline Breech presentation & 02 & - \\
\hline Bad obstetric history & 02 & - \\
\hline Twin pregnancy & 02 & - \\
\hline $\begin{array}{l}\text { Intrauterine growth } \\
\text { restriction }\end{array}$ & 01 & - \\
\hline Severe preeclampsia & 01 & 02 \\
\hline $\begin{array}{l}\text { Non-reassuring fetal } \\
\text { heart rate }\end{array}$ & - & 02 \\
\hline Severe MS & 01 & - \\
\hline Severe AS & 01 & - \\
\hline
\end{tabular}

The most common lesion in patients with RHD was mitral stenosis seen in $51(53.1 \%)$ followed by mitral stenosis with mitral regurgitation with $\mathrm{PAH}$ in 36 
$(37.5 \%)$ patients. The surgical correction was done prior to pregnancy in 6 patients, 4 underwent closed mitral valvotomy for MS and 2 had ASD closure. Among congenital heart disease, most of them 9 (17.9\%) were ASD (Table 2).

Most of the patients, $78(66.6 \%)$ had spontaneous vaginal delivery, 3 patients had VBAC. In 12 patients, ventouse was applied to cut short the second stage of labour (Figure 2). Caesarean section was done in 28 (23.9\%) patients. Majority of them were elective, done for obstetric indications. Previous caesarean section was the most common indication in $10(35.7 \%$ ) cases (Table3).

The maternal complications were seen in $69(58.9 \%)$ pregnant women. Majority of cases 54 (46.2\%) were associated with anaemia followed by preeclampsia in $20.5 \%$ and preterm in $12.8 \%$ cases. The other obstetric complications seen were previous LSCS (11.1\%), Placenta preavia (2.56\%), hypothyroidism (5.12\%), breech $(2.56 \%)$, twin pregnancy $(1.71 \%)$, postpartum haemorrhage $(5.12 \%)$. Cardiac complications were seen in $29(24.8 \%)$ cases out of which 18 required ICU care. The most common cardiac complications seen was congestive cardiac failure (CCF) in 23 (19.6\%) cases. Among the 23 patients with $\mathrm{CCF}, 12$ patients had anaemia, 6 had preeclampsia. Of the 18 patients requiring ICU care, 12 patients recovered and there were 6 maternal deaths $(5.12 \%)$.

Table 4: Associated maternal complications.

\begin{tabular}{|lcll|}
\hline $\begin{array}{l}\text { Obstetrics } \\
\text { complications }\end{array}$ & Booked & Unbooked & Total \\
\hline Anaemia & 21 & 33 & $54(46.2 \%)$ \\
\hline Preeclampsia & 09 & 15 & $24(20.5 \%)$ \\
\hline Preterm & 08 & 07 & $15(12.8 \%)$ \\
\hline Previous LSCS & 09 & 04 & $13(11.1 \%)$ \\
\hline Placenta preavia & 03 & 00 & $03(2.56 \%)$ \\
\hline Hypothyoidism & 02 & 04 & $06(5.12 \%)$ \\
\hline Breech & 02 & 01 & $03(2.56 \%)$ \\
\hline Twin pregnancy & 02 & 00 & $02(1.71 \%)$ \\
\hline $\begin{array}{l}\text { Postpartum } \\
\text { Haemorrhage }\end{array}$ & 02 & 04 & $06(5.12 \%)$ \\
\hline $\begin{array}{l}\text { Cardiac } \\
\text { complications }\end{array}$ & Booked & Unbooked & Total \\
\hline $\begin{array}{l}\text { Congestive } \\
\text { cardiac failure }\end{array}$ & 08 & 15 & $23(19.6 \%)$ \\
\hline $\begin{array}{l}\text { Atrial } \\
\text { fibrillation }\end{array}$ & 02 & 01 & $03(2.56 \%)$ \\
\hline $\begin{array}{l}\text { Pulmonary } \\
\text { arterial } \\
\text { hypertension } \\
\text { (PAH) }\end{array}$ & 01 & 02 & $03(2.56 \%)$ \\
\hline $\begin{array}{l}\text { Maternal } \\
\text { mortality }\end{array}$ & 02 & 04 & $06(5.12 \%)$ \\
\hline
\end{tabular}

Among these four were cases of term pregnancy with severe mitral stenosis with severe anaemia in CCF, two being unbooked cases presented in labour. The other two were unbooked cases of severe $\mathrm{MS}+\mathrm{MR}+\mathrm{PAH}$ with severe preeclampsia with intrauterine fetal demise in labour. Complications were seen more among unbooked patients in contrast to booked cases (Table 4).

The small for gestation age was seen in 15 (12.8\%) babies. A total of 33 babies required NICU care. There were 9 perinatal deaths, of which 4 were intrauterine deaths ( 2 at term, 1 at 36 weeks, 1 at 28 week) and 5 neonatal death ( 3 had severe birth asphyxia, died within 72 hour of birth, 2 were preterm with low birth weight with jaundice). Two IUDs were seen in mothers with RHD with PAH with severe preeclampsia, other two were unexplained. Poor neonatal outcome seen in unbooked patients with associated obstetric complications (Table 5).

Table 5: Neonatal outcome.

\begin{tabular}{|c|c|c|c|}
\hline Complications & Booked & Unbooked & Total \\
\hline $\begin{array}{l}\text { Small for } \\
\text { gestation age } \\
\text { (SGA) }\end{array}$ & 06 & 09 & $15(12.8 \%)$ \\
\hline $\begin{array}{l}\text { NICU } \\
\text { admission }\end{array}$ & 11 & 22 & 33 \\
\hline Birth asphyxia & & & $12(28.2 \%)$ \\
\hline Prematurity & & & 09 \\
\hline IUGR & & & 06 \\
\hline APGAR <7 & & & 06 \\
\hline $\begin{array}{l}\text { Perinatal } \\
\text { mortality }\end{array}$ & 03 & 06 & $\begin{array}{l}09(7.7 \%) \\
(04-I U D) \\
(05- \\
\text { Neonatal } \\
\text { death) }\end{array}$ \\
\hline
\end{tabular}

\section{DISCUSSION}

In the present study, we determined the type of cardiac lesion and assessed the fetomaternal outcome in pregnant women with cardiac disease. Cardiac disease continues to be a risk factor for maternal and neonatal mortality and morbidity. The incidence of cardiac disease at our centre was $0.8 \%$. In the study by Sheela et al, the incidence of cardiac disease in pregnancy was $1 \% .{ }^{9}$ Most of them were primigravida $(61.5 \%)$ and $(66.6 \%)$ were booked cases. Majority of the patients $(71.8 \%)$ were in NYHA class I and II. Similar findings were seen in other studies. ${ }^{11,12}$ Hsieh et al in their study reported that out of the total feto maternal deaths $75 \%$ were in patients with NYHA class III and IV. ${ }^{13}$ In our study, predominant lesion was rheumatic heart disease $(82.1 \%)$, MS being the most common $(53.1 \%)$. Similar results were noted in the studies by Mahesh et al $(44.6 \%)$ and by Nilajkumar et al $(55 \%){ }^{7,10}$ Congenital heart disease accounted for $17.9 \%$ of cases, among which ASD was most common (42.9\%). Similar results were seen in studies by Sheela et al and Nilajkumar et al patients underwent surgical correction before pregnancy out of them 4 underwent closed mitral 
valvotomy and 2 had ASD closure. ${ }^{6,7,9}$ In our study, most of the women had spontaneous vaginal delivery. The Caesarean section was performed in 28 (23.9\%) cases mostly for obstetrical indications. The second stage was cut short by instrumentation in $10.3 \%$ of patients, 3 $(2.56 \%)$ patients had VBAC.

Majority of cases were associated with anaemia (46.2\%) followed by preeclampsia $(20.5 \%)$ that worsened the underlying cardiac lesion during pregnancy. Complication being more in unbooked patients in contrast to booked cases. Thus, the early diagnosis and treatment of complications as anaemia and preeclampsia can improve the outcome. Studies done by various authors have shown similar results..$^{7-10,14-16}$ The cardiac complications were noted in $29(24.8 \%)$ patients out of which 23 (19.6\%) developed congestive cardiac failure, 3 developed atrial fibrillation and another 3 had pulmonary arterial hypertension (PAH). Among 18 patients treated in intensive care unit, 12 patients recovered and 6 died. Out of the 6 maternal mortality seen, 4 were cases of term pregnancy with severe mitral stenosis with severe anaemia in CCF, two being unbooked cases presented in labour. The other two were unbooked cases of severe $\mathrm{MS}+\mathrm{MR}+\mathrm{PAH}$ with severe preeclampsia with intrauterine fetal demise in labour which could have been prevented by early detection and timely intervention. The above finding suggest lack of awareness among the community about the heart disease and complications during pregnancy. Similar finding were seen in studies done by Mahesh et al. ${ }^{10}$

The small for gestation age was seen in $15(12.8 \%)$ babies. Total $33(28.2 \%)$ babies were admitted to NICU. The perinatal mortality was $7.7 \%$ in our study. The results were comparable to the studies done by Mahesh et al, Hanania et al and Suri at al. ${ }^{10,17,18}$ Despite the potential for significant maternal morbidity in most patients with cardiac disease, satisfactory outcome can be expected with careful antenatal, intrapartum and postpartum management. ${ }^{19}$

\section{CONCLUSION}

Cardiac disease in pregnancy is a high risk condition which has a major impact on pregnancy and its outcome. This study results conclude that Rheumatic heart disease is still a predominant cardiac problem affecting the pregnancy and its outcome. The early detection, treatment, proper follow up and correction prior to pregnancy shall improve the outcome and decrease the maternal morbidity and mortality in heart disease. Maternal and perinatal morbidity and mortality can be reduced with early and frequent antenatal care in coordination with the cardiologist. The early detection and management of non-cardiac complications shall have a major impact on improvement of outcome.

Educating the community about the cardiac disease and its complications, need for early detection of cardiac lesion, close follow up during antenatal period, intrapartum and postpartum care plays a vital role.

Funding: No funding sources

Conflict of interest: None declared

Ethical approval: Not required

\section{REFERENCES}

1. Cunningham FG, Leveno KJ, Bloom SL, Hauth JC, Rouse DJ, Spong CY, editors. Cardiovascular Disease In Williams Obstetrics. $24^{\text {th }}$ edition. McGraw Hill Education; New York; 2010.

2. James, Steer, Weiner, Goink, Crowther, Robson. High risk pregnancy management option. In Cardiac disease in pregnancy. $4^{\text {th }}$ edition: 2012;627-656.

3. Bhatla, Yadav, Mishra. The cardiac case. In Ian Donald's practical obstetrics problems. $6^{\text {th }}$ edition. BI Publications Pvt Ltd. India. 2010;103-126.

4. Davies GA, Herbert WN. Assessment and management of cardiac disease in pregnancy. J Obstet Gynaecol. 2007;29(4):331-6.

5. Burlingame J, Horiuchi B, Ohana P, Onaka A, Sauvage LM. The contribution of heart disease to pregnancy-related mortality according to the pregnancy mortality surveillance system. J Perinatal. 2012;32:163-9.

6. Surge D, Blake S, Donald D. Pregnancy complicated by maternal heart disease at the National maternity Hospital, Dublin 1969-1978. Am J Obst Gyne. 1981;139(1):1-6.

7. Barbosa PJ, Lopes AA, Feitosa GS. Prognostic factors of rheumatic mitral stenosis during pregnancy and puerperium. Arq Bras Cardiol. 2000;75:215-24.

8. Sawhney H, Aggarwal N, Suri V, Vasishta K, Sharma Y, Grover A. Maternal and perinatal outcome in rheumatic heart disease. Int $\mathbf{J}$ Gynaecology Obstet. 2003;80:9-14.

9. Sheela CN, Karanth S, Patil CB. Maternal cardiac complications in women with cardiac disease in pregnancy. Int. J Pharma Biomed Res. 2011;2(4),261-5.

10. Koregeol M, Nina, Nayak R, Amritha. Maternal and perinatal outcomes of pregnancies complicated by cardiac disease. J Turkish German Gynaecol Assoc. 2009;10:30-4.

11. Vasu S, Stergiopoulos K. Valvular heart disease in pregnancy. Hellenic J Cardiol. 2009;50:498-510.

12. Bhatla N, Lal S, Behra G, Kriplani A, Mittal S, Agarwal N, et al. Cardiac Disease in pregnancy. Int J Gynaecol Obstet. 2003;82:153-9.

13. Hsieh TT, Chen KC, Soong JH. Outcome of pregnancy in patients with organic heart disease in Taiwan. Asia Oceania J Obstet Gynaecol 2007; 19:21-7.

14. Kovavisarach E, Nuaplot P. Outcome of pregnancy among parturients complicated with heart disease in Rajavithi hospital. J Med Assoc Thai. 2007;90:22539 . 
15. Sermer M, Colman J, Siu S. Pregnancy complicated by heart disease: a review of Canadian experience. J Obstet Gynaecol. 2003;23:540-4.

16. Nqayana T, Moodley J, Naidoo DP. Cardiac disease in pregnancy. Cardiovasc J Afr. 2008;19:145-51.

17. Hanania G, Thomas D, Michel PL, Garbarz E, Age C et al. Pregnancy and prosthetic heart valves a French cooperative retrospective study of 155 cases. Eur Heart J. 1994;15:1651-8.
18. Suri V, Sawhney H, Vasistha K, Renuka T, Grover A. Pregnancy following cardiac valve replacement surgery. Int J Gynaecol Obstet. 1999;64:239-46.

19. Siu S, Sermer M, Colman J, Alvarez AN, Mercier LA, Mortan BC, et al. Cardiac disease in pregnancy (CARPREG) investigators. Prospective multicenter study of pregnancy outcome in women with heart disease. Circulation. 2001;104:515-21.

Cite this article as: Pandey K, Verma K, Gupta S, Jahan U, Kirti N, Gupta P. Study of pregnancy outcome in women with cardiac disease: a retrospective analysis. Int J Reprod Contracept Obstet Gynecol 2016;5:3537-41. 